\title{
Conceito do Produto a Partir da Pesquisa de Mercado: Fonte Geradora de ENERGIA EM BICICLETAS
}

Ariane Marques Mauricio (arianemauricio@hotmail.com) - Centro Universitário de Belo Horizonte (UNIBH).

Allan Santos Farias (allansaints@ufmg.br) - Laboratório Integrado de Design e Engenharia do Produto, Departamento de Engenharia de Produção, Universidade Federal de Minas Gerais (LIDEP/DEP/UFMG)

Lucas Augusto Ribeiro Souza Sena (1s.augustto@gmail.com) - LIDEP/DEP/UFMG

Douglas Gonçalves Monteiro dos Santos (gms.douglas@hotmail.com) - LIDEP/DEP/UFMG

Eduardo Romeiro Filho (romeiro@dep.ufmg.br) LIDEP/DEP/UFMG

\section{RESUMO}

As tecnologias para geração de energia limpa são uma demanda premente para a sociedade atual. Da mesma forma, mudanças no cenário do mundo do trabalho requerem soluções técnicas que atendam às necessidades de grupos de trabalhadores em progressiva precarização. A partir deste cenário, este artigo apresenta um estudo visando o projeto conceitual de um dínamo para bicicletas, voltado para a utilização por entregadores que fazem uso de bicicletas. Esta categoria profissional destaca-se, entre outras coisas, pela precarização das condições de trabalho e, paradoxalmente, por sua importância em um cenário onde o isolamento social é uma estratégia fundamental para a saúde pública. Este projeto, inicialmente voltado a usuários de bicicletas de forma geral, demonstrou a oportunidade de um produto voltado para esta prática profissional, a partir de uma perspectiva de inovação frugal. São apresentados as pesquisas realizadas e os primeiros resultados em âmbito informacional, que darão base ao "briefing" do produto a ser desenvolvido.

Palavras chave: Dínamo para Bicicletas; Briefing; Metodologia de Projeto;Inovação frugal 


\section{INTRODUÇÃO}

O dínamo é uma tecnologia bastante antiga e sua utilização como meio de geração de energia elétrica a partir de energia mecânica, sendo que as versões mais antigas datam da primeira metade do século XIX. Sua utilização para geração de energia elétrica por meio de bicicletas é amplamente disseminada, sendo obrigatórios por lei na Alemanha (HUHN, 2013). Existem diversas soluções técnicas, a partir de uma abordagem de "inovação frugal”, que utilizam dínamos como geradores de energia em situações onde o acesso à eletricidade é restrito (KANNAN et al., 2012). Também são comuns dínamos acoplados em bicicletas para, por exemplo, gerar energia para faróis ou luzes traseiras (SUHALKA et al., 2014).

A bicicleta, por sua vez, retoma uma posição de destaque como meio de transporte, em situações urbanas onde representa vantagem comparando o tempo de deslocamento em distâncias curtas, considerando os problemas de congestionamento no tráfego urbano (ROSENBERG ASSOCIADOS, 2015). Estudo realizado no Brasil pelo extinto Ministério das Cidades (2007) indica que a bicicleta possui no país quatro abordagens principais: Lazer, Esporte, Brinquedo e Meio de transporte para as pessoas de baixa renda. Geralmente, a bicicleta é encarada como um meio limpo, eficiente e de baixo custo para transporte (em áreas suburbanas ou rurais). Entretanto, ao contrário da imagem "verde" que o transporte por bicicleta pode ter junto à classe média, esta tem se tornado um elemento importante como fonte de renda para um crescente grupo de trabalhadores altamente precarizados, os entregadores de encomendas (especialmente alimentos) por aplicativos. Estes trabalhadores normalmente enfrentam grandes jornadas de trabalho, em condições insalubres e dependem totalmente da comunicação por telefone celular para a realização de suas tarefas (DESGRANGES, 2021).

A partir deste cenário, este artigo apresenta o processo de desenvolvimento do conceito para um dínamo para bicicletas, realizado por um grupo de pesquisa de uma universidade brasileira. A formulação do problema proposto foi "o desenvolvimento de um sistema técnico que permita a geração de energia suficiente para os faróis e lanternas traseiras da bicicleta e recarga de aparelhos eletrônicos utilizados durante os percursos". $\mathrm{O}$ objetivo inicial era voltado para pessoas que utilizam a bicicleta como forma de lazer, mas as pesquisas indicaram uma necessidade mais relevante do ponto de vista social, ou seja, os trabalhadores precarizados do crescente setor de entregas. $\mathrm{O}$ artigo descreve o processo de pesquisa de mercado, algumas ferramentas de projeto utilizadas e, ao final, apresenta 
elementos de projeto em seu âmbito informacional, que darão base ao um "briefing" do produto a ser desenvolvido.

\section{METODOLOGIA}

Para o desenvolvimento do projeto, foram adotados procedimentos comuns observados na literatura relacionada ao design de produtos, notadamente Baxter (1995), Cross (1994), Malhotra (2001, para pesquisa de mercado), Medeiros (1981), Munari (1975), Romeiro et al. (2010) e Roozenburg e Eekels (1995). As etapas do projeto foram definidas a partir de Medeiros (1981), como formulação do problema, síntese das informações, geração de ideias, avaliação das soluções propostas e execução do projeto detalhado. Neste artigo serão abordadas as etapas de formulação do problema, análise e síntese, que resultarão na elaboração do briefing que inclui informações como a natureza e o contexto do projeto, análise da indústria, mercado consumidor, objetivos de negócios, estratégia de design e outras (PHILIPS, 2008), constituindo-se de uma ferramenta para definição do conceito do produto e base para a geração de ideias.

Com o objetivo de obter informações junto aos usuários, foram realizadas pesquisas com usuários de bicicletas, utilizando questionários, para gerar os dados necessários para atingir os objetivos do projeto (Parasuraman, 1991). Foram elaboradas perguntas seguindo alguns pontos básicos citados por Manzato e Santos (2012), assim, iniciando a pesquisa com a identificação do entrevistado e, em seguida, sendo colocados filtros selecionando o universo a ser pesquisado (usuários de bicicletas). Para o tratamento das informações levantadas na pesquisa de mercado, diversas ferramentas foram utilizadas: a criação de "personas" (WILLIAMS et al., 2014), o painel semântico (REIS e MERINO, 2020, JACQUES e SANTOS, 2009), mapa preço-valor (IIDA, 1998) e a matriz morfológica (SCHERER et al., 2014, HSIAO e KO, 2013).

\section{RESULTADOS E DISCUSSÃO}

Neste item é apresentada a aplicação das ferramentas utilizadas para o desenvolvimento do conceito do produto. O objetivo é avaliar a relevância e a contribuição de cada uma para o resultado obtido.

\subsection{Levantamento de mercado}

Para o desenvolvimento do produto, norteou-se por dados levantados quanto ao mercado de consumo de bicicletas e acessórios. Assim, foi utilizado um questionário para 
observar o comportamento e as demandas dos usuários de bicicletas. O questionário contou com 15 perguntas, abertas e fechadas, e com o seguinte esquema, exposto na figura abaixo:

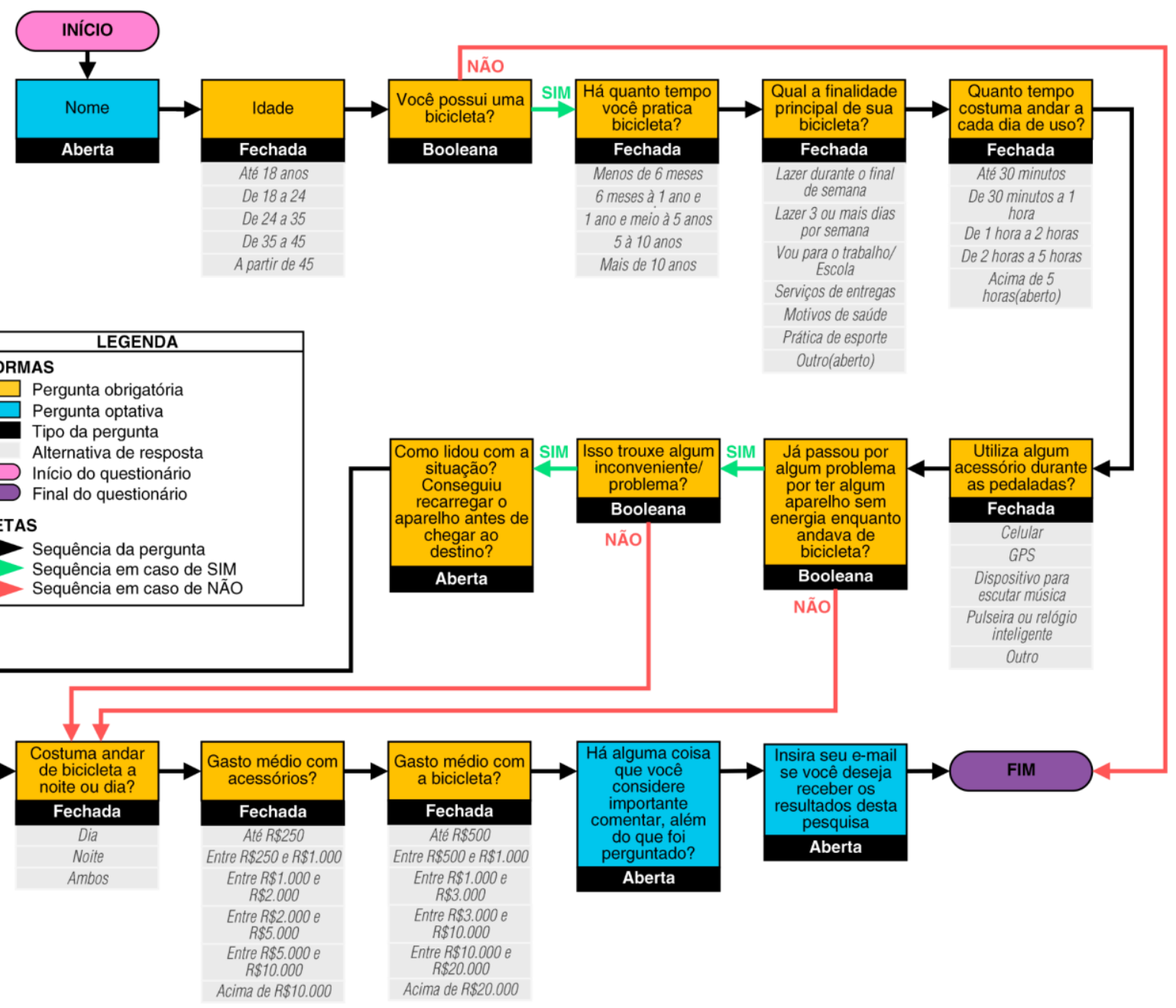

FIGURA 1 - Resumo esquemático do questionário

Foram recebidas 35 respostas no questionário, um público 54,3\% feminino e 45,7\% masculino, majoritariamente entre 25 e 35 anos. Grande parte dos respondentes utilizam a bicicleta há, pelo menos, um ano e meio e 68,7\% utilizam ao menos um acessório eletrônico (principalmente celulares) durante o uso da bicicleta. Outro dado importante é que $74,2 \%$ dos respondentes já gastaram acima de $\mathrm{R} \$ 250,00$ em acessórios, além de 48,3\% terem gasto acima de $\mathrm{R} \$ 500,00$, indicando disposição para investimento em acessórios.

Destaca-se que metade destes respondentes já passaram por falta de carga em algum dispositivo ao longo de seus deslocamentos com bicicletas, com 56,2\% dos ciclistas tendo inconvenientes associados à falta de energia em seu aparelho eletrônico. Associa-se a isso o fato de que $62,5 \%$ dos respondentes utilizam a bicicleta no período noturno, em que há 
necessidade de iluminação e sinalização, além de menor disponibilidade de serviços em casos de emergências, traz à tona a necessidade por um meio de recarga portátil.

Realizou-se um levantamento de produtos concorrentes e similares (tabela 1). Assim, percebeu-se que não há no mercado nacional um produto com a proposta do projeto, ou seja, uma solução de captação, transformação e armazenamento de energia. Com base em dados de especificações destes modelos similares, foi desenvolvida a tabela 2, fase inicial do Mapa Preço-valor (IIDA, 1998).

\begin{tabular}{|c|c|c|c|c|}
\hline Nome & Preço (R\$) & Saída(V) & Saída(A) & $\begin{array}{c}\text { Local de } \\
\text { instalação }\end{array}$ \\
\hline Dínamo Panasonic (Sanyo) H27 & 375,00 & & & Cubo da roda \\
\hline Dínamo SON 28 & $1.360,00$ & 6 & 0,5 & Cubo da roda \\
\hline Dínamo SONdehx & $1.180,00$ & 6 & 0,5 & Cubo da roda \\
\hline Dínamo SONdelux 12 & $1.600,00$ & 6 & 0,5 & Cubo da roda \\
\hline Cubo Shimano DH-UR708-3D & 597,49 & 6 & 0,5 & $\begin{array}{c}\text { Cubo da roda } \\
\text { dianteira }\end{array}$ \\
\hline Cubo Shimano DH-S501 & 574,37 & 6 & 0,5 & Cubo da roda \\
\hline $\begin{array}{l}\text { SHIMANO NEXUS DH-C3000-2N- } \\
\text { QR }\end{array}$ & & 6 & 0,4 & Cubo da roda \\
\hline $\begin{array}{c}\text { Dínamo Bicicleta Tradicional } \\
\text { (Sem marca) }\end{array}$ & 89,90 & 12 & 0,46 & $\begin{array}{l}\text { Banda de } \\
\text { rodagem do } \\
\text { pneu }\end{array}$ \\
\hline Supernova Infinity S Hub Dynamo & $1.099,52$ & & & Cubo da roda \\
\hline CARREGADOR E-WERK & $1.320,00$ & & & \\
\hline ACUMULADOR E-WERK & 590,00 & & & \\
\hline
\end{tabular}

TABELA 1 - produtos concorrentes e similares.

TABELA 2 - Tabela de análise-valor.

\begin{tabular}{|c|c|c|c|c|c|c|c|}
\hline Nome & Preço & Bateria & $\begin{array}{l}\text { Facilidade de } \\
\text { instalação }\end{array}$ & Durabilidade & Peso & Aparência & Acessibilidade \\
\hline Dínamo Panasonic (Sanyo) H27 & 8 & 0 & 2 & 8 & 1 & 6 & 5 \\
\hline Dínamo SON 28 & 3 & 0 & 2 & 9 & 4 & 6 & 5 \\
\hline Dínamo SONdelux & 4 & 0 & 2 & 9 & 5 & 6 & 5 \\
\hline Dínamo SONdelux 12 & 2 & 0 & 2 & 9 & 5 & 6 & 5 \\
\hline Cubo Shimano DH-UR708-3D & 7 & 0 & 2 & 8 & - & 6 & 7 \\
\hline Cubo Shimano DH-S501 & 7 & 0 & 2 & 8 & 3 & 6 & 2 \\
\hline SHIMANO NEXUS DH-C3000-2N-QR & - & 0 & 2 & 8 & 1 & 6 & 2 \\
\hline Dinamo Bicicleta Antiga (S/M) & 10 & 0 & 5 & 7 & 0 & 6 & 8 \\
\hline Supernova Infinity S Hub Dynamo & 5 & 0 & 2 & 8 & 5 & 6 & 2 \\
\hline Carregador E-WERK & 3 & 0 & 4 & 8 & 9 & 0 & 5 \\
\hline Acumulador E-WERK & 7 & 3 & 6 & 6 & 6 & 0 & 5 \\
\hline Bicicleta Vanhawks & 0 & 0 & 10 & 10 & 10 & 10 & 0 \\
\hline Mochila Solar - Eco Soli & 8 & 10 & 10 & 6 & 4 & 8 & 5 \\
\hline Bolsa Solar - Eco Soli & 9 & 4 & 10 & 6 & 5 & 7 & 5 \\
\hline Flying to the Sun - Bolsa Sustentável & - & 4 & 10 & 5 & 6 & 5 & 1 \\
\hline
\end{tabular}


A pontuação atribuída considerou o preço máximo como nota " 0 ” e o menor como nota "10", sendo os valores intermediários inseridos em uma escala. Os dispositivos Shimano Nexus DH-C3000-2N-QR e Flying to the sun - Bolsa Sustentável não possuem nota no quesito, por não apresentarem valor de venda, por estarem sem estoque e pelo fato dos pedidos serem feitos por encomenda, respectivamente. A pontuação de bateria é semelhante, onde a falta da capacidade representa " 0 " e a maior capacidade o valor " $10 "$.

Para facilidade de instalação foi considerado como "10", todos os produtos que não requerem nenhuma intervenção para poder serem utilizados em sua totalidade, como nota "2" os componentes que requerem um profissional para sua instalação, como nota "4" a "6" os componentes que poderiam ser instalados pelo próprio usuário, a variar do seu nível de dificuldade, como uso de suportes e outros. No quesito durabilidade foi considerado o material de fabricação e a avaliações feitas por usuários disponíveis na internet, sendo os produtos de materiais metálicos e fibra de carbono melhor avaliados, e os plásticos, tecido ou que envolvem placas solares expostas, avaliados com notas inferiores.

O critério de peso foi também avaliado como o maior peso " 0 " e o menor " 10 ", dentro de categorias próprias, o que justifica a bicicleta Vanhawks (fabricada em fibra de carbono) atingir nota "10", mesmo sendo mais pesada que os dínamos. Vale mencionar que a Shimano não fornece informações de peso quanto ao Cubo DH-S501. A característica de aparência é um critério relativo, que foi baseado em análise de avaliações dos produtos disponíveis na internet. A acessibilidade foi baseada na disponibilidade de cada produto, produtos disponíveis apenas por importação receberam notas menores, e produtos com larga distribuição em varejistas no Brasil foram melhor avaliados.

Com base nos valores atribuídos a cada característica de cada produto, podemos afirmar que nenhum dos produtos atende às demandas de "um dispositivo portátil, para uso cotidiano do ciclista possuindo geração limpa e eficiente de eletricidade", seja por não oferecer uma solução completa, necessitando de outros equipamentos associados (como no caso dos dínamos, inversores e baterias), além da busca por componentes compatíveis entre si. Outros produtos esbarram nos impedimentos de custo e disponibilidade, que as tornam inviáveis na prática, como é o caso da bicicleta vanhawks.

\subsection{Personas}


Baseadas nas entrevistas e coletas de informação, foram formuladas três personas procurando abranger e entender a maior parte do público estudado e como a elaboração do dínamo impactaria a vida delas. $\mathrm{O}$ uso de personas se torna interessante pois é possível "construir o usuário" a partir de um estereótipo, pois os usuários são pessoas diferentes da equipe de projeto, embora tenham empatia (NIELSEN, 2009). A seguir, são descritas as três personas criadas a partir da pesquisa com usuários.

Persona 01 - Neto: Homem de 25 anos que trabalha como entregador de aplicativos, atua entregando alimentos utilizando bicicleta. Ele trabalha de 12 a 16 horas por dia. Por ser um trabalho que exige esforço físico, utiliza roupas leves e tênis, buscando maior conforto. Uma ferramenta essencial é o telefone celular, já que ele recebe os pedidos pelo aparelho e utiliza o GPS para encontrar o local da entrega. Porém, devido a longa jornada de trabalho, a duração da bateria se torna um problema, pois em muitas ocasiões ela acaba durante o expediente.

Persona 02 - Enzo: Estudante do Ensino Superior de 19 anos, ele utiliza a bicicleta para ir para a faculdade, para fins recreativos e pretende começar a se locomover utilizando bicicleta para economizar tempo e dinheiro com passagem de ônibus, além de promover um estilo de vida mais saudável e com baixo impacto ambiental. Uma das dificuldades encontradas por ele é conseguir realizar o trajeto utilizando fones de ouvido e o GPS sem que parte significativa da sua bateria descarregue.

Persona 03 - Camila: Mulher de 30 anos, graduada e trabalha como administradora, que utiliza um automóvel para se locomover para o trabalho. Nos fins de semana ela costuma fazer "trilhas" de bicicleta, utilizando um celular para ter acesso ao GPS e as suas músicas, além de um fone de ouvido portátil. Por fazer trilhas em locais mais afastados, uma de suas preocupações é ficar sem bateria durante o percurso.

Com a elaboração das personas, foi possível uma avaliação mais criteriosa das condições reais de uso do produto e das motivações para adoção e compra pelos usuários. A experiência demonstrou estar em acordo com a literatura, pois a empatia possibilitada pelas personas facilitou a abstração, pela equipe, de idiossincrasias pessoais dos projetistas (quais as motivações e frequência de uso, por exemplo) e serviu de base para discussões mais consistentes. 


\subsubsection{Painel Semântico}

O Painel Semântico é usado (CASSIDY, 2008) como definição estética do objeto e instrumento de visualização e comunicação na equipe, tornando-a uma importante ferramenta para o desenvolvimento do produto. A fim de contextualizar o uso do produto e tornar possível a "visualização" das personas desenvolvidas, foram elaborados painéis semânticos direcionados para as três personas definidas (figuras 2, 3 e 4). Esses painéis semânticos visam aproximar a equipe e criar empatia com a rotina, estilo de vida e preferências do público-alvo estudado.

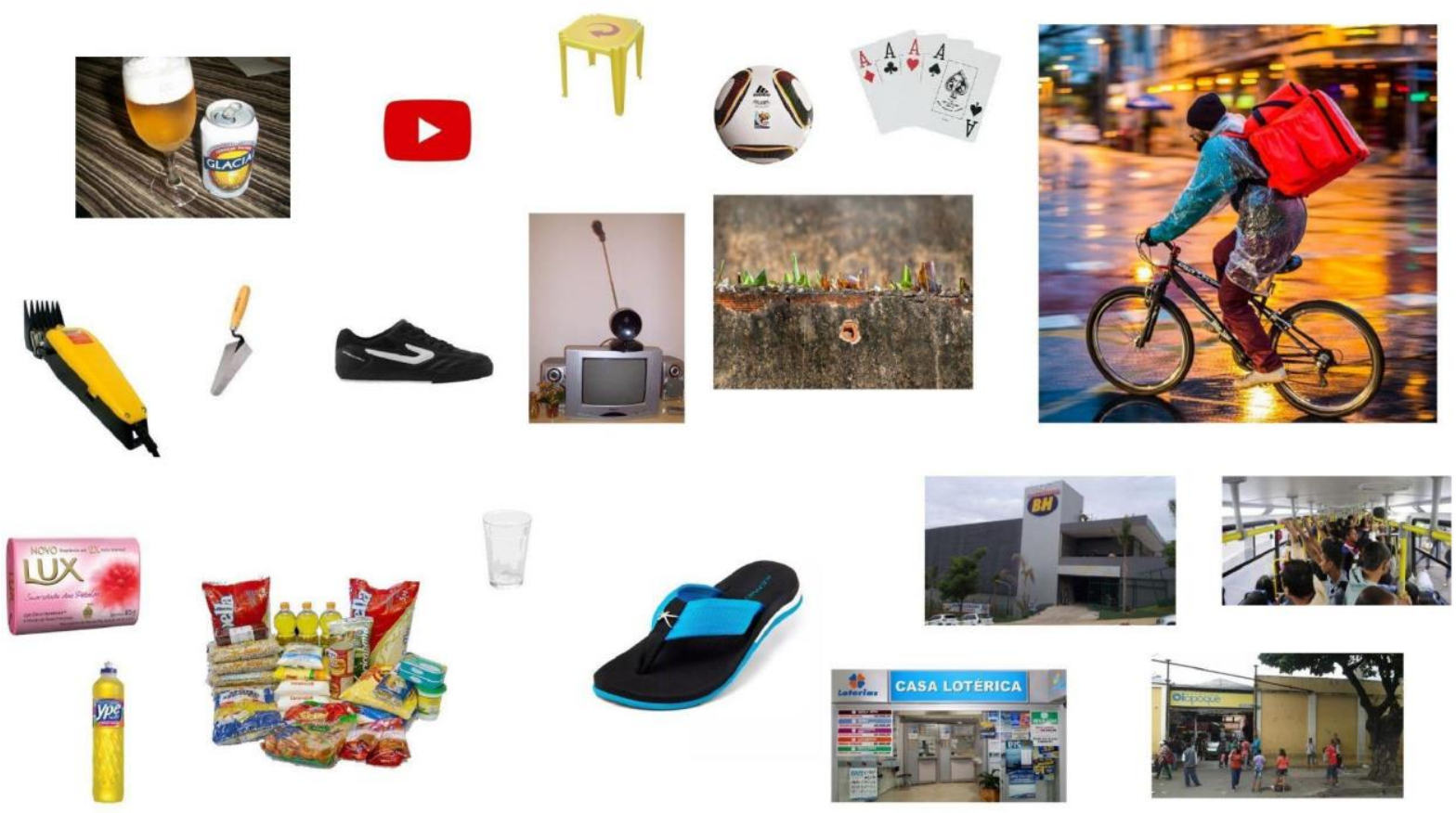

FIGURA 2 - Painel Persona 01: Neto (entregador). Fonte: Os autores. 


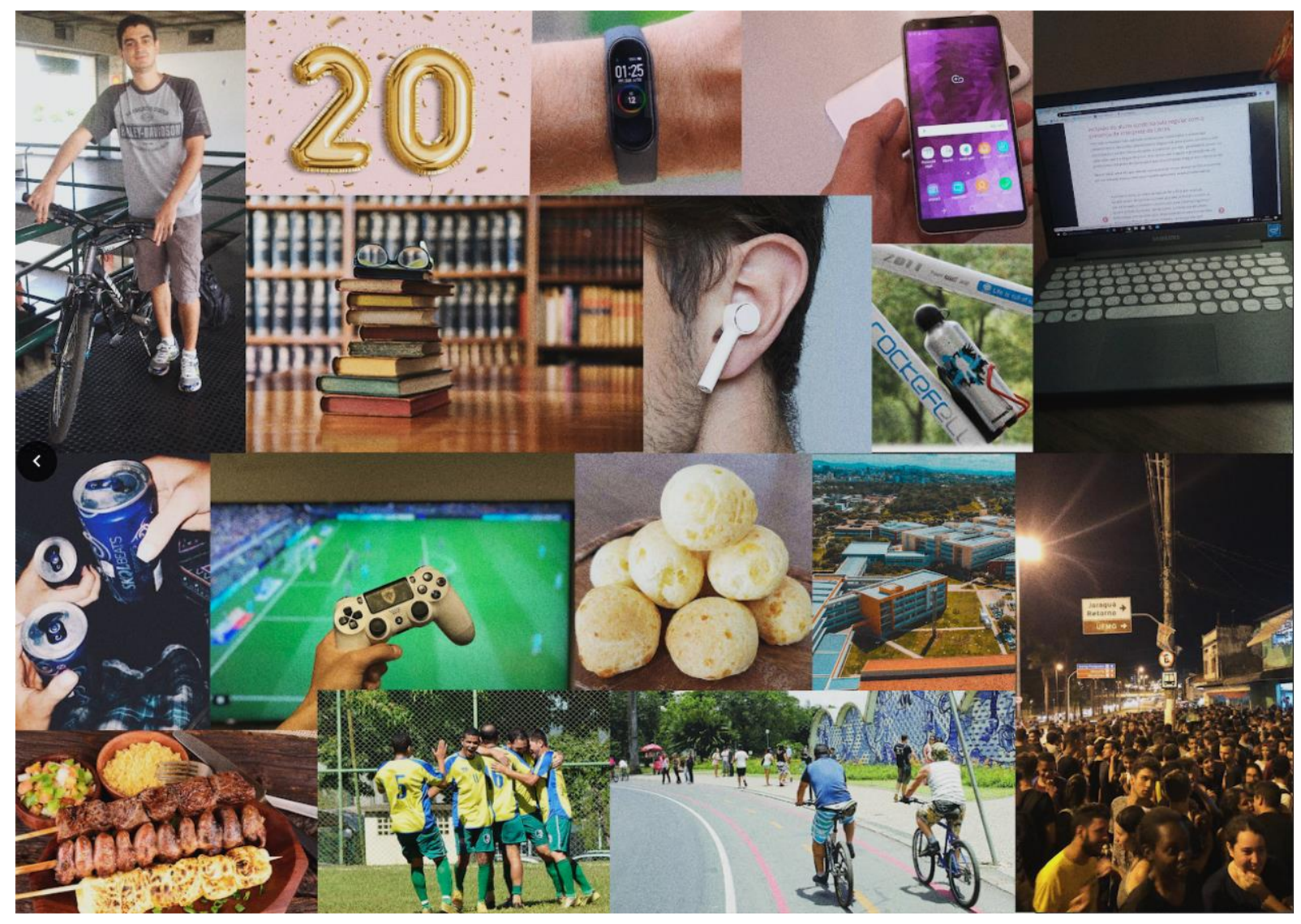

FIGURA 3 - Painel Persona 02: Enzo (estudante). Fonte: Os autores.
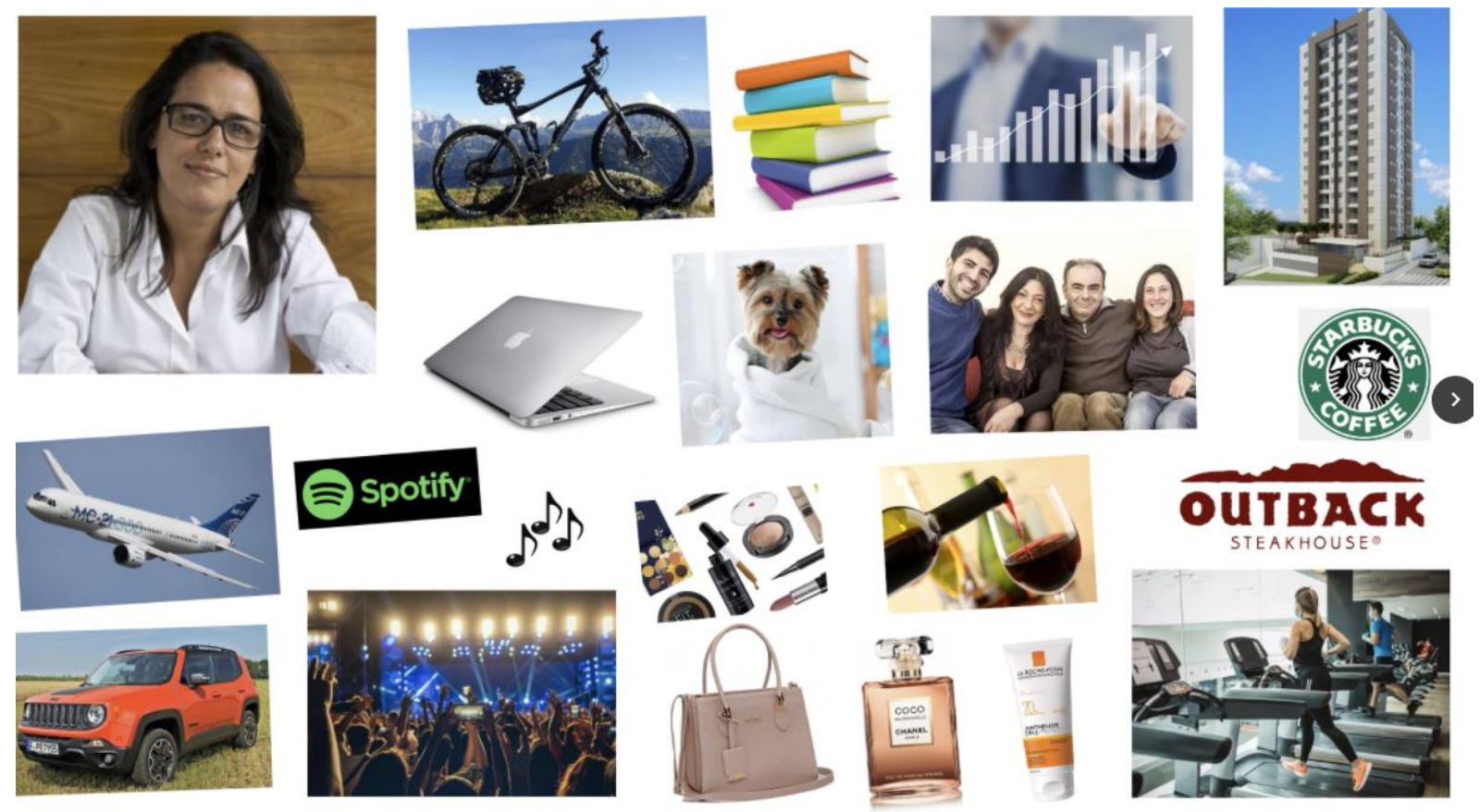

FIGURA 4 - Painel Persona 03: Camila (administradora). Fonte: Os autores. 


\subsection{Matriz Morfológica}

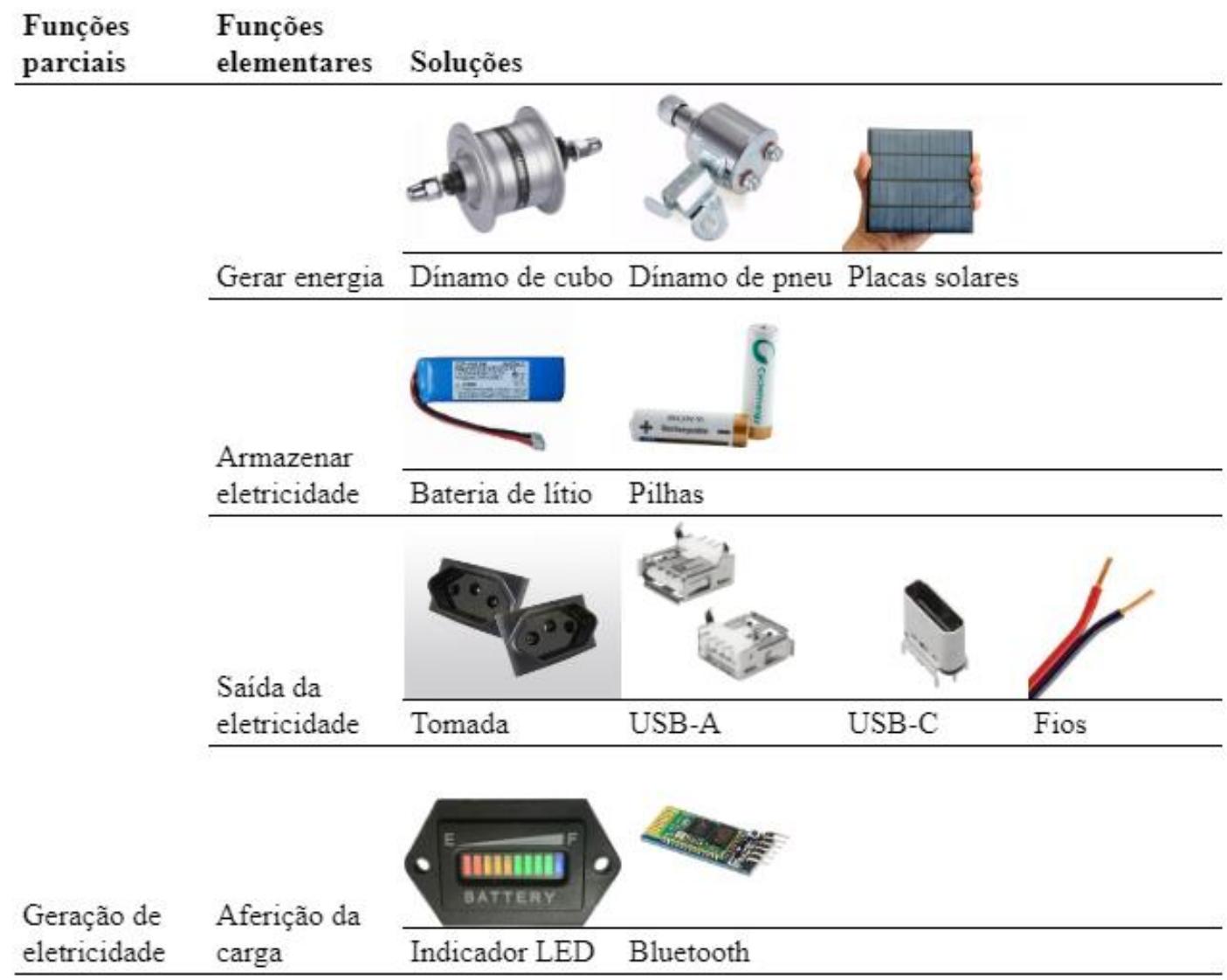

FIGURA 5 - Tabela de matriz morfológica

Baseado em demandas observadas nas etapas anteriores, foi utilizado a matriz morfológica (YAN, 1998), que explana os objetivos da ferramenta, sendo enfatizado a busca por soluções parciais para funções dadas e estudo das características destas soluções, permitindo a análise morfológica, onde se busca dividir o problema em subproblemas, facilitando a visualização de soluções de maneiras individualizadas.

\subsection{Pesquisa direcionada com usuários}

Com os resultados obtidos nas pesquisas com usuários de bicicletas e a definição das personas foi feito contato com possíveis usuários com perfil representante de cada persona para uma nova pesquisa direcionada, com o objetivo de conhecer mais profundamente o público, no formato de entrevistas abertas semiestruturadas por telefone ou por "chat" em aplicativo. 
Relacionado à persona 01, foram três entrevistados com idades entre 29 e 34 anos, que trabalham para uma cooperativa de serviços de entrega via bicicleta. Essa persona caracterizase pela utilização da bicicleta para trabalhar fazendo entregas para aplicativos e como um meio de transporte barato e mais acessível. É um perfil que geralmente não possui condições de grandes investimentos em bicicletas e acessórios, mas que têm uma grande necessidade de equipamentos que os ajude no dia a dia devido à rotina de trabalho perigosa e exaustiva, já que costumam pedalar mais de $200 \mathrm{~km}$ por semana. Todos relataram problemas relacionados à falta de energia nos celulares.

Para a segunda persona 02, foi entrevistado um jovem de 19 anos, solteiro, graduando no Ensino Superior, que utiliza a bicicleta como transporte para faculdade e de forma recreativa. $\mathrm{O}$ entrevistado costuma pedalar durante e aos finais de semana de forma recreativa e prática de exercícios físicos. Mesmo não percorrendo longas distâncias diariamente, a bicicleta tem um papel constante devido à recorrência de sua utilização. Disse que costuma andar em locais urbanos, sempre utilizando o celular com GPS e fones de ouvido. Ele percorre cerca de 8 quilômetros por dia durante a semana e 15 quilômetros aos finais de semana, totalizando em média $260 \mathrm{~km}$ por mês. Por utilizar GPS e fones de ouvido relata problemas com bateria do celular, principalmente no trajeto de retorno para casa.

A entrevistada para persona 03 é uma mulher casada, com dois filhos, administradora e empresária, considerada um exemplo de pessoa adulta de classe média que usa bicicleta na prática de esporte. A entrevistada informou que anda pela manhã, quatro vezes por semana, por volta de $30 \mathrm{~km}$ diários. Costuma andar em locais urbanos, utilizando o celular com GPS e/ou algum guia de treino e por isso "a bateria do celular sempre acaba no meio do percurso". Este é um perfil de pessoas dispostas a investir dinheiro em prol do esporte buscando a qualidade da corrida. Segundo a entrevistada, sua família possui seis bicicletas e ela já gastou mais de 30 mil reais no modelo que ela utiliza e em acessórios como capacete, cinta cardíaca, relógio ou "camelback" para água, frisando que a qualidade dos produtos é o mais importante para o conforto e a segurança do praticante. Ela deu exemplos de situações onde se perdeu no caminho ou não conseguiu fazer contato com outras pessoas por falta de bateria e que sem dúvidas compraria um produto que convertesse a energia da corrida para carregar o celular e a ajudasse chegar até o final do treino.

Ao grupo de projeto chamou a atenção especialmente a persona 1 (entregador). Em 2020 o LABMOB (Laboratório de Mobilidade Sustentável/PROURB-UFRJ) em parceria com a Aliança Bike (Associação Brasileira do Setor de Bicicletas) realizou uma pesquisa com 270 
entregadores e traçou um perfil desse trabalhador: $53 \%$ possuem ensino médio, $40 \%$ o ensino fundamental, 4\% têm nível superior e 16\% estudam atualmente (supletivo, cursos profissionalizantes e graduação), tendo em média 24 anos, sendo que $71 \%$ são negros, trabalham em média 12 horas por dia e recebem em média 936 reais por mês (ALIANÇA BIKE, 2019). Arcam com custo de acessórios essenciais como capacete, capa de chuva, bagageiro, kit para trocar câmara furada, luzes sinalizadoras, óculos, mochila e luvas. Além dos itens de manutenção básicos, como pneus em bom estado e freios regulados. Quando perguntados sobre os gastos com reparos e acessórios, os entrevistados disseram que gastam entre 50 e 100 reais por mês. Informaram também que sempre têm problemas com celular sem energia, o que causa dificuldades para encontrar um endereço ou se comunicar com alguém. Ao serem questionados sobre as maiores dificuldades notadas, além do sol e da chuva e o trânsito perigoso, um dos entrevistados deixou claro toda a precarização vivida por eles:

" Falta ponto de apoio para recarregar o celular e uso do banheiro, falta custear a alimentação, falta fornecer equipamentos para profissionalização do trabalho de entrega (capacete, capa). Faltam fornecer produtos de higiene (água sanitária e álcool 70\%), falta precarizar menos o trabalho e garantir o mínimo de respeito. Todos esses custos hoje recaem sobre o entregador, falta muita paciência dos clientes, pois imprevistos acontecem e estão ligados a essa precarização. Não enxergar isso é compactuar com a exploração do entregador, falta garantir direitos trabalhistas".

\section{CONCLUSÃO}

Este artigo apresentou algumas ferramentas de projeto utilizadas na definição de um conceito de produto, base para a preparação de um "briefing". As ferramentas aplicadas mostraram-se adequadas ao objetivo proposto e em suas relações para a consolidação das informações levantadas. É interessante observar que as informações levantadas na pesquisa junto aos usuários foram utilizadas de forma integrada ao uso de ferramentas que auxiliaram a compreensão correta das necessidades dos usuários e das características necessárias ao produto a ser desenvolvido.

Com relação às características que nortearão o briefing, pode-se definir o produto como "um sistema técnico capaz de gerar energia a partir do movimento da bicicleta, sendo capaz de (1) sustentar sistemas de iluminação dianteira (faróis) e traseiras (lanternas), e gerar carga para pequenos equipamentos eletrônicos, notadamente celulares. O grande problema 
será o preço que, para atender aos entregadores, não deverá ser superior a $R \$ 300,00$, ou seja, metade do preço dos produtos concorrentes, instalados no cubo da roda. Será também necessário um "inversor", que transforme a energia em corrente contínua (DC) do dínamo para corrente alternada (AC) para alimentar os demais equipamentos. Por fim, será(ão) necessária(s) saída(s) USB para alimentação dos equipamentos. Daí considera-se que uma abordagem centrada na inovação frugal seja essencial ao sucesso do projeto.

A partir destas premissas, alguns croquis (figura 6) foram elaborados como primeira solução conceitual para o produto: seu eixo será fixado às hastes da roda dianteira da bicicleta em dois pontos, sendo a energia, depois de passar pelo inversor, será transmitida à bateria (ou diretamente destinada à recarga), de onde será transmitida ao aparelho eletrônico por meio de uma saída USB (figura 7). Será desenvolvido também um suporte para celulares, fixado no guidão da bicicleta. Estes itens serão vendidos separadamente, o que possibilitará ao usuário montar o aparelho segundo suas necessidades, ou mesmo ir adquirindo partes ao longo do tempo.

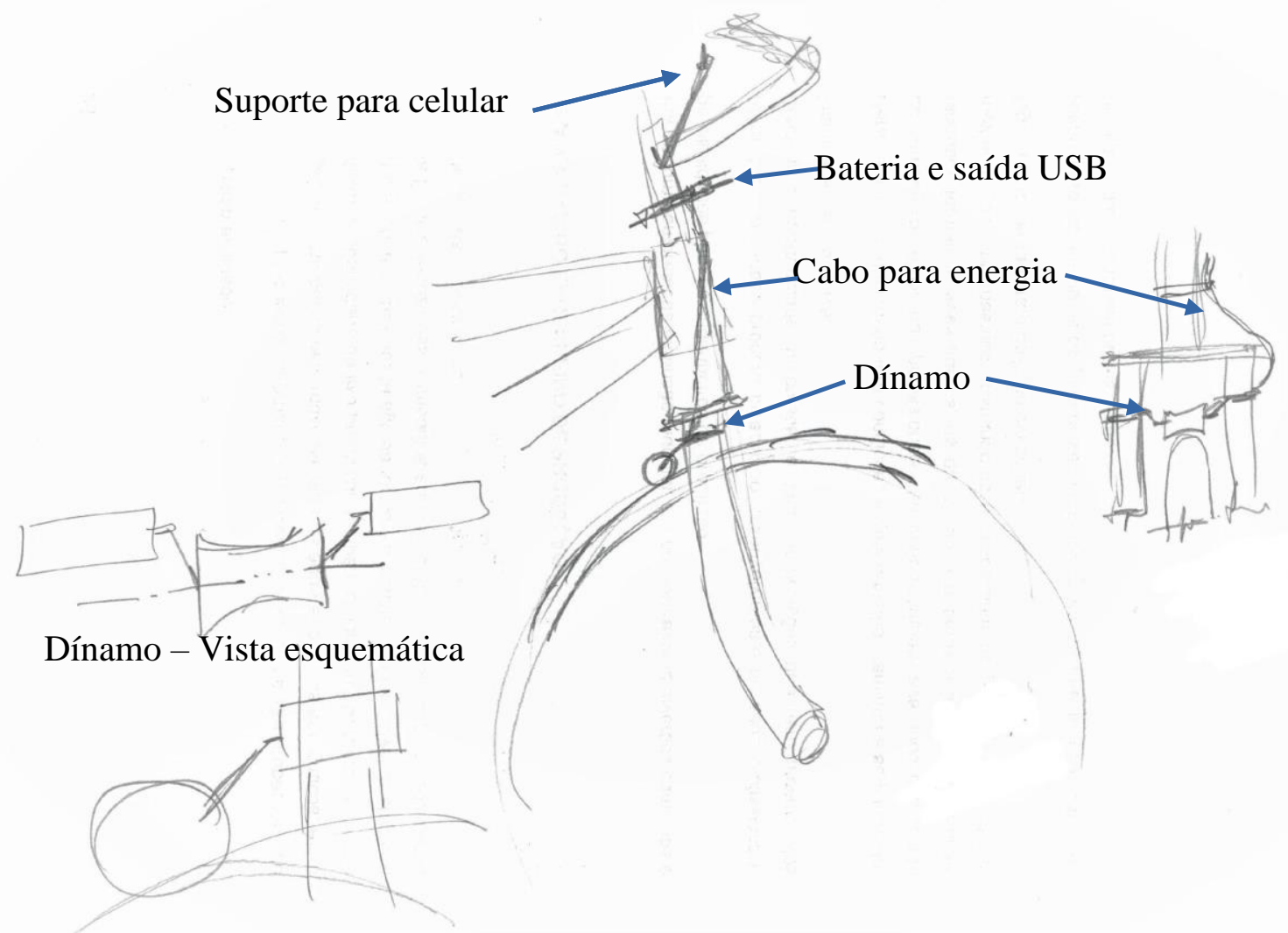

FIGURA 6 - Croqui gerado a partir do conceito de produto desenvolvido 
VISTA LATERAL

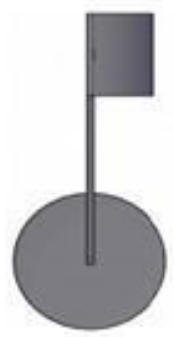

DÍNAMO
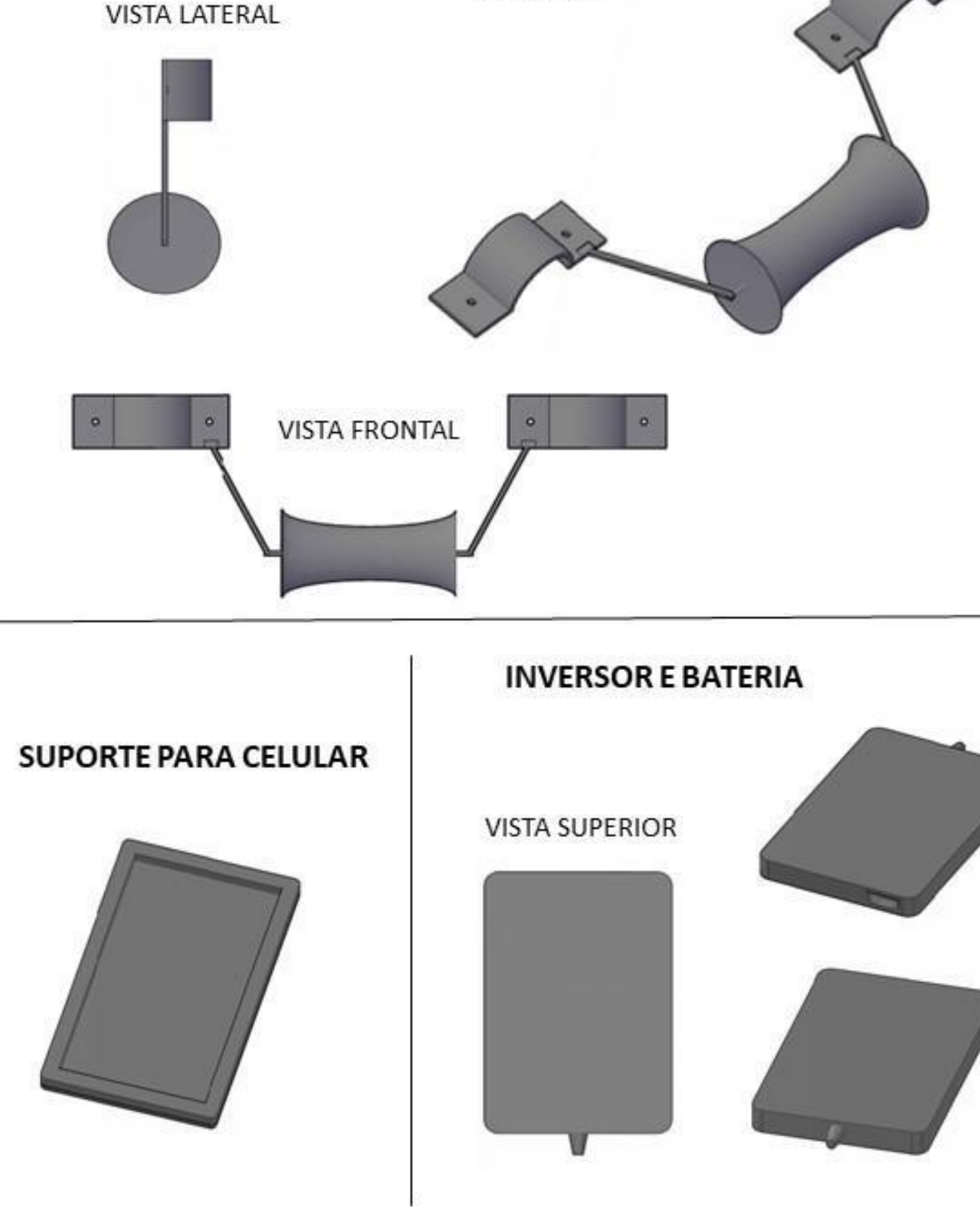

INVERSOR E BATERIA

VISTA SUPERIOR
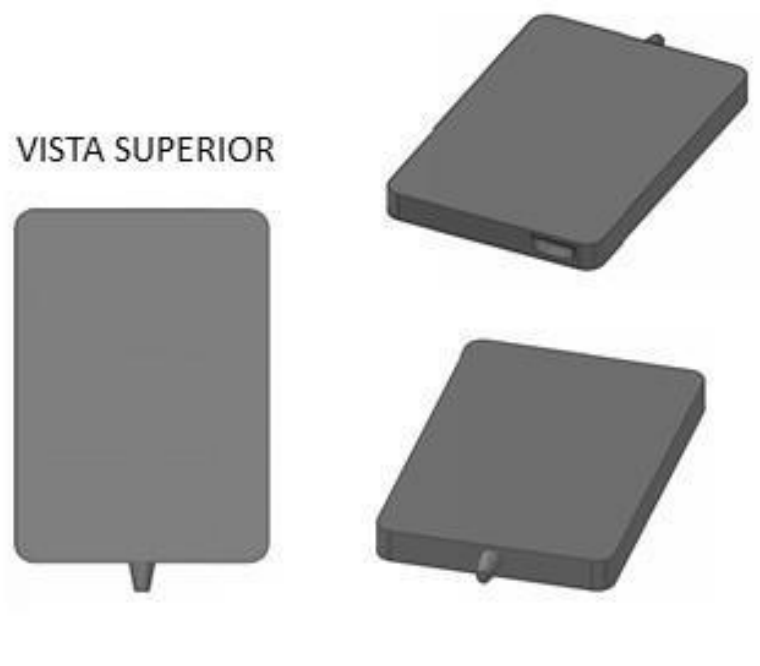

FIGURA 7 - Estudo para desenho de componentes do produto desenvolvido

\section{AGRADECIMENTOS}

Os autores agradecem à Professora Johelma Pires de Avelar pela orientação da equipe e à Áurea Carolina Ferreira pela colaboração no projeto. Agradecemos também aos entrevistados que contribuíram para a pesquisa. 


\section{REFERÊNCIAS}

BAXTER, M. Product design - practical methods for the systematic development of new products. London: Chapman \& Hall, 1995.

CROSS, N. Engineering design methods: strategies for product design. 2. ed. Londres: Wiley,1994. 179p.

DESGRANGES, N. Os algoritmos do empreendedorismo: A plataformização do trabalho de entregadores de iFood. Pensata: Revista dos Alunos do Programa de Pós-Graduação em Ciências Sociais da UNIFESP, [S. l.], v. 9, n. 2, 2021. DOI: 10.34024/pensata.2020.v9.11136. Disponível em: https://periodicos.unifesp.br/index.php/pensata/article/view/11136. Acesso em: 14 jun. 2021.

HSIAO SW, KO, YC, A study on bicycle appearance preference by using FCE and FAHP International Journal of Industrial Ergonomics https://doi.org/10.1016/j.ergon.2013.04.003 2013

HUHN, R. Nighttime Cycling: Accidents, Lights, and Laws in Europe In: Proceedings, International Cycling Safety Conference 2013. 20-21 November 2013, Helmond, The Netherlands, 2013. Disponível em https://web.archive.org/web/20161104211501/http://www.beezodogsplace.com/wp-

content/uploads/2014/10/huhn2013_Nighttime-Cycling-Accidents.pdf Acesso em 14 de maio, 2021.

IIDA, I. O mapa preço-valor. Estudos em Design, 6(2)47-56, 1998.

JACQUES, JJ., SANTOS, RF. Metáforas gráficas - a aplicação do painel semântico no desenvolvimento de produtos. Educação Gráfica, 13(2)245-257, 2009

KANNAN, RAJESH, MEGGALINGAM, PRANAV SREEDHARAN VRLIYARA, RAGHAVENGRA MURLI PRABHU, ROCKY KATOCH, "Pedal Power Generation" International Journal of Applied Engineering Research, Vol. 7 No. 11, 2012.

LABMOB; ALIANÇA BIKE. CIClOlOGíSTICA BRASIL. Laboratório de Mobilidade Sustentável PROURB-UFRJ; Associação Brasileira do Setor de Bicicletas. São Paulo, Abril de 2020. Disponível em: CICLOLOGISTICA-RELATORIO-280420.pdf (ufrj.br).

MALHOTRA, Naresh. Pesquisa de Marketing - Uma Orientação Aplicada. $3^{\mathrm{a}}$ ed. Porto Alegre: Bookman, 2001.719p.

MEDEIROS, Estevão Neiva. Uma Proposta de Metodologia para o Desenvolvimento de Projeto de Produto. (Dissertação, Mestrado em Engenharia de Produção). Rio de Janeiro: COPPE, UFRJ, 1981.

MINISTÉRIO DAS CIDADES. Programa Brasileiro de Mobilidade por Bicicleta - Bicicleta Brasil. Caderno de Referência para elaboração de Plano de Mobilidade por Bicicleta nas Cidades. Brasília: Secretaria Nacional de Transporte e da Mobilidade Urbana, 2007.

MUNARI, B., Diseño e Comunicación Visual: Contribución a una metodología didáctica. Barcelona: Editorial Gustavo Gilli S.A., $3^{a}$ edição, 361 p. 1975.

NIELSEN, L. Personas. Copenhagen: Snitker \& Co, 2009. Disponível em https://www.personas.dk/wpcontent/uploads/2019/11/personas-til-load.pdf Acesso em 17 de maio, 2021.

PHILIPS, P. Briefing: a gestão do projeto de design. São Paulo: Editora Blucher,2008

REIS, MR. MERINO, EAD. Painel semântico: revisão sistemática da literatura sobre uma ferramenta imagética de projeto voltada à definição estético-simbólica do produto. Estudos em Design (online). 28(1)178-190, 2020.

ROMEIRO FILHO, E.; FERREIRA, C. V.; GOUVINHAS, R. P.; NAVEIRO, R. M.; CAUCHICK, P. Projeto do Produto. Rio de Janeiro: Elsevier, 2010. 
ROOZENBURG, N. F. M.; EEKELS, J. Product Design: Fundamentals and Methods. New York: John Wiley \& Sons, 1995. 408 p.

ROSENBERG ASSOCIADOS. O uso de bicicletas no Brasil: qual o melhor modelo de incentivo? Brasília: Associação Brasileira dos Fabricantes de Motocicletas, Ciclomotores, Motonetas, Bicicletas e Similares - Abraciclo, 2015. Disponível em https://www.abraciclo.com.br/site/estudo-rosenberg-ouso-de-bicicletas-no-brasil-qual-o-melhor-modelo-de-incentivo/ Acesso em 23 de abril 2020.

SCHERER et al., Possibilidades de uso da matriz morfológica no processo de geração de alternativas em design. P\&D Design - Congresso Brasileiro de Pesquisa e Desenvolvimento em Design, 2014.

SUHALKA, R. KHANDELWAL M.C., SHARMA K.K., SANGHI, A. Generation of Electrical Power using Bicycle Pedal. International Journal of Recent Research and Review, Vol.VII, Issue 2, June 2014 Disponível em http://ijrrr.com/papers7-2/10-Generation\%20of\%20Electrical\%20Power\%20using\%20Bicycle\%20Pedal.pdf Acesso em 18 de maio, 2021.

WILLIAMS, I,et al. "A Collaborative Rapid Persona-Building Workshop: Creating Design Personas with Health Researchers. International Journal of Sociotechnology and Knowledge Development (IJSKD) 6(2)17-35. http://doi.org/10.4018/ijskd.2014040102, 2014

ZWICKY, Fritz. Morphological Astronomy. Berlin: Springer - Verlag, 1957.

YAN, H. S. Creative Design of Mechanical Devices. Singapore: Springer, 1998. 